\title{
Beer Purchase Decisions AND CONSUMPTION BEHAVIOR
}

\author{
Christy A. Williams and Paul G. Barretta
}

\begin{abstract}
Using observational research, field experiment, and consumer survey, perceptions and behaviors of beer consumers are measured, comparing craft beer consumers to mass market beer consumers. Findings indicate that craft beer consumers tend to value the experience of both consuming and shopping for beer whereas mass market beer consumers take more of a utility perspective. Furthermore, there is evidence that the use of retail displays may have different effects for each product category.
\end{abstract}

Keywords: Beer consumption, Craft beer, Premium beer, Mass market beer, Retail display.

DOI: http://dx.doi.org/10.15239/j.brcadvjb.2018.03.01.ja04

\section{INTRODUCTION}

Although sales for the U.S. beer industry remain flat, craft breweries have been increasing in number and impact, their market share by volume rising from $5 \%$ in 2010 to $11 \%$ in 2014 (Davis, 2016). The purpose of this 
study is to take an exploratory look into the perceptions and behaviors of craft beer consumers compared to consumers of mass market beer; we use the industry term "premium" for mass marketed beer. This comparison is investigated using three methods: observational research, field experiment, and web-based consumer survey. Field research was conducted in partnership with a beer distributor in West New York state (WNY) and one of its key accounts (regional grocery chain, permitted by state geographic area to sell beer). Observational research was conducted in the same geographic area to maintain consistency with the same consumer base; results from the observational research were used to inform a web-based survey with further reach.

In addition to measuring perceptions and behaviors of craft and premium beer consumers, another potentially important point of exploration is the notion that locally brewed beers might carry some weight with consumers, as indicated by a Harris Poll conducted by Nielsen in 2015.

"Consumers' desire to search for and buy local is growing. Among all alcoholic beverage categories, local has grown in importance the most among beer drinkers. In fact, $22 \%$ of beer drinkers said they think the importance of being made locally has grown over the last couple of years, compared with $14 \%$ of wine drinkers and only $5 \%$ of spirit drinkers."

(Nielsen, 2015)

\section{Literature Review}

\section{Craft Beer}

After the U.S. beer industry went through a three-decade period of concentration leading to an oligopoly (Greer, 1981), the 1990's saw a rise of microbreweries, and with it wider selection for consumers, innovations in products brewed, and expanded employment opportunities (Carroll \& Swaminathan, 2000). Craft beer, particularly in comparison to mass- 
market beer, is a product category that has also come to the attention of researchers focusing on markets in a number of countries. One general consistency is a focus on what determines a craft beer, where consumers focus on taste, production, and ingredients while industry sources focus on production and brewer, though not where the ingredients are sourced (Donadini \& Porretta, 2017). This point about where ingredients are sourced will be discussed further in the Buy Local section.

From a customer perspective there is not a clear understanding of the differences between mass market and craft beers, but generally craft beer is more of an experience while mass market is seen more as utility (Gómez-Corona, Escalona-Buendía, García, Chollet, \& Valentin, 2016). A study consistent with this perspective compared two approaches to craft beer consumer preferences and found that independent variables related to brand equity explained more variance than independent variables related to product attributes or utility (Orth \& Lopetcharat, 2005). One description of craft beer perceptions includes six dimensions: it is a multisensory experience; is the focal point of consumption, usually at-home or at a special event or activity; is the product of high quality and local production; is focused on the attributes of the product such as distinct flavor, texture, and packaging; is consumed either alone or with very selective co-consumers; has low availability, and to non-connoisseurs is expensive and impractical (Gómez-Corona, et al., 2016).

An important element of craft beer perception is its accompanying identity. Largely relying on a nostalgic view of taverns and community (Lamertz, Foster, Coraiola, \& Kroezen, 2015), this identity has been propagated by both marketers and consumers writing in public spaces (Rice, 2016). The opportunity to create a variety of unique versions of this identity has provided strategies for product differentiation by brand (Clemons, Gao, \& Hitt, 2006). One unique differentiating element has been found to be the personality of an entrepreneur who produces a craft brew (Miller, Munoz \& Hurt, 2016). The craft beer sector continues to thrive, and has attracted the attention of major breweries who have 
begun acquiring smaller breweries (Choo, 2016) which, ironically, means they can no longer be given craft beer status (Brewers, 2017).

\section{Buy Local}

One element of attraction for consumers of craft beer is the notion that it is a local product (Bastian et al., 1999). This can be linked to microbrewers taking advantage of niche market opportunities (Tremblay, Iwasaki, \& Tremblay, 2005) created by concentration of the overall beer marketing referenced above (Greer, 1981). Consumers seem to have latched on to the notion that craft beers represent a narrative of a small brewer with some element of roots that are deemed to be conceptually local (Rice, 2016), and produced with local grains (Donadini \& Porretta, 2017).

Even though the larger Buy Local movement is based on a more specific notion of locality and food sourcing, the craft beer industry has benefited from the association (Rice, 2016). The greater Buy Local mindset has been found to be appealing for more than consumers pre-disposed to buy locally grown products, dispelling anecdotal criticism and creating awareness of associated benefits and barriers (Knight, 2013). Buy Local activists have developed a narrative that buying local products is a more ethical and socially positive form of consumption, even though there are elements that are left unchecked and not properly portrayed (Blake, Mellor, \& Crane, 2010; McCaffrey \& Kurland, 2015). While there are economic benefits to be gained from Buy Local campaigns (Routon, Hartley, \& Berry, 2016; Ruane, 2014), the pragmatic associations between the craft beer industry and the general perceptions of Buy Local, both economic and social, may not be as strong as their perception.

\section{ReseARCh OBJEctives ANd Methodology}

The research questions to be answered by the present research are:

(1) Who is the core premium beer consumer?

(2) Who is the core craft beer consumer? 
(3) What motivates the premium beer consumer to purchase?

(4) What motivates the craft beer consumer to purchase?

(5) Does merchandising affect beer purchase decisions?

Our qualitative research objectives are to identify both premium beer and craft beer consumers as well as find out what motivates them to purchase; this was accomplished using observational research with the opportunity to ask questions of consumers. The results of qualitative research and knowledge informed by previous research informed the design of a web survey and field experiment to gather quantitative data. The objectives of the web survey were to determine what factors affect willingness to purchase premium beer and craft beer. The field experiment would assist us in determining whether or not cross-category displays (of beer) increase sales of premium beer, craft beer, both premium and craft beer, or neither premium nor craft. For the sake of this study, a cross-category display is a singular display with premium beer and craft beer merchandised together in some form. This paper will describe each study, including method and findings. This will be followed by a discussion section, including implications for theory and practice as well as industry recommendations, and conclude with limitations and directions for future research.

\section{ObSERVATIONAL Research}

To better understand behavior of various beer consumers, we used observational research with questions. Our qualitative research objectives were to identify the following: (1) the core premium beer consumer (2) what motivates the premium beer consumer to purchase (3) what WNY beer consumers consider local (4) the core craft beer consumer and (5) what motivates the craft beer consumer to purchase beer.

Four specific retail locations of a major beer outlet in the WNY area were chosen based on similarities in geography and store sales. These four stores offered a good cross-section of beer products, including both craft 
and premium brands. It is important to note that these particular stores sell beer, flavored malt beverages, ciders and non-alcoholic beverages as well as snacks and ice. First author of this paper performed the observational research in each location to ensure consistency in questioning within the stores. Four days were chosen to visit each of the four stores: two Friday evenings between the hours of 5 and 7 PM and two Saturday afternoons between the hours of 12 and 2 PM. Between one and two hours were spent in each store. Once in the store, the goal was to observe behavior leading up to the beer purchase decision and (if possible) ask questions after checkout.

The observation was kept discreet. The researcher stood at a distance, took field notes and only approached a consumer after he or she had made a purchase. If given the opportunity to speak with a consumer, the researcher always made sure he or she was comfortable and willing to speak before moving forward with questioning. Some examples of the questions asked are as follows:

(1) What did you purchase today and why?

(2) What is your deciding factor when choosing a beer?

(3) Do you plan your beer purchase decisions ahead of time or while in store?

(4) Do you drink any local beer brands?

These were general questions which oftentimes lead to follow-up and probing questions; generally speaking, every consumer who was willing to answer questions responded to the above. At the conclusion of the observational research, data analysis began. Notes from each store were compared to identify common themes as well as inconsistencies.

\section{COMMON THEMES}

Most consumers who purchased premium beer spent little time in the store, moving directly to the premium beer section upon entering the 
store and oftentimes, purchased this beer cold. When asked why brand X or brand Y, common premium beer consumer responses were, "I like it," or "It's my favorite beer," or in one instance, "It's all I ever eat." Although female consumers did purchase premium beer as well, the majority of the premium beer consumers were male, middle-aged and older. Many of the consumers who purchased craft beer were young males; however, it is important to note that there was greater diversity in the typical demographics such as gender, age, etc. among craft beer customers than there was among premium beer customers. The majority of the consumers who purchased craft beer spent more time in the store and admitted to "just browsing." Furthermore, craft beer consumers were more likely to engage in conversation with store personnel, oftentimes asking questions, listening intently and sharing stories. Common responses to why a specific beer was chosen included, "I wanted to try something new" or "I heard it was good." Throughout this particular research much of the behavior and many of the purchase decisions were consistent within segments. In other words, more times than not, premium beer consumers had behaviors similar to one another, as did craft beer consumers.

Overall findings from observational research indicate that premium beer purchases are more likely to be planned or habitual. On the other hand, craft beer purchase decisions tend to be made in store and consumers prefer variety. Craft beer consumers appear to value information, including expertise and advice from store personnel. An indication of observation research, therefore, is that premium beer consumers and craft beer consumers display differences in their purchase decision and behavior.

\section{Field Experiment}

The first quantitative method we used was a field experiment. Retail displays were used as an experimental variable to measure potential effects of in-store displays on premium beer and craft beer. In-store displays included the term Buffalocal, which is a term that is pending 
34 BRC Journal of Advances in Business Vol. 3, No. 1

trademark by the beer distributor cooperating with this research. The field experiment was used to test the following hypotheses:

\section{Preview Complete}

This completes the limited preview of this paper. Please visit the link below to purchase.

\section{Citation Information}

Williams, Christy A., and Paul G. Barretta. "Beer Purchase Decisions and Consumption Behavior." BRC fournal of Advances in Business 3, no. 1 (2018): 51-72. http://dx.doi.org/10.15239/j.brcadvjb.2018.03.01.ja04

\section{Web APPE ndix}

A web appendix for this paper is available at: http://dx.doi.org/10.15239/ j.brcadvjb.2018.03.01.wa04 